\title{
O desafio do regime de colaboração no novo Plano Nacional de Educação
}

\author{
The challenge of collaborative arrangment in the new National \\ Education Plan
}

El desafio del pacto de colaboración en el nuevo Plan Nacional
de Educación

Luiz Araujo'

\section{Resumo}

Este artigo discute os desafios do regime de colaboração no contexto do novo Plano Nacional de Educação, aprovado pela Lei Federal 13.005/2014. Partindo do reconhecimento de que o modelo de federalismo brasileiro é uma combinação entre o desejo de descentralização de poder e a histórica primazia do papel regulador e indutor do poder central em nosso país, o artigo evidencia como se deu o debate sobre o regime de colaboração no PNE e qual o cenário futuro desenhado a partir do plano. Por fim, o texto conclui destacando que o enfrentamento às desigualdades educacionais, agravadas pelo modelo federativo atual, passa por rever o papel da União no financiamento da educação, mas especialmente, passa pelo desenvolvimento de políticas redistributivas reguladas pelo governo central, única forma de induzir comportamentos mais equânimes na aplicação dos recursos na área educacional.

Palavras-chave: Regime de Colaboração; Federalismo; Plano Nacional de Educação; Financiamento da Educação.

\begin{abstract}
:
This article discusses the challenges of collaborative arrangement in the new National Education Plan, approved by Federal Law 13.005/2014. Recognizing that the Brazilian federalism model is a combination of the desire of power decentralization and the historical primacy of the central regulatory role and power of the inductor in our country, the article shows how was the debate on the collaborative arrangment in PNE and what the future scenario drawn from the plane. Finally, the text concludes highlighting that the solution to educational inequalities, aggravated by the current federal model, needs the revision of the Union's role in education financing, but especially through the development of redistributive policies regulated by the central government, that is the only way to induce more equitable behavior in the application of resources in education.
\end{abstract}

Keywords: Collaborative arrangment; Federalism; National Education Plan; Education financing. 


\section{Resumen:}

Este artículo aborda los desafíos del pacto de colaboración en el nuevo Plan Nacional de Educación, aprobado por la Ley Federal 13.005/2014. Reconociendo que el modelo del federalismo brasileño es una combinación de la voluntad de descentralización del poder y la primacía histórica del papel regulador central del poder central en nuestro país, el artículo muestra cómo fue el debate sobre el pacto de colaboración en PNE y como será el escenario futuro dibujado por el plan. Por último, el texto concluye destacando que enfrentar las desigualdades educativas, agravados por el modelo federativo actual, incluye revisar el papel de la Unión en la financiación de la educación, pero en especial a través del desarrollo de políticas redistributivas regulados por el gobierno central, como la única manera de inducir un comportamiento más equitativo en la aplicación de los recursos en la educación.

Palabras-clave: Pacto de colaboración; Federalismo; Plan Nacional de Educación; Financiamiento de la Educación.

\section{Introdução}

O debate sobre regime de colaboração está circunscrito à forma de funcionamento do federalismo brasileiro. Conceituar um país como federal é difícil, pois existe uma clara dificuldade para construir uma formulação que fosse aceita universalmente, inclusive mesmo a teoria política encontraria dificuldade para precisar qual seria a divisão de poder adequada e o formato institucional correto para que dado Estado possa ser denominado de federado (FIORI, 1995).

Mas em todas as definições sobre federalismo estão presentes algumas características, dentre elas a existência de uma

(...) dupla autonomia territorial do poder político, ou seja, na qual se distinguem duas esferas autônomas de poder: uma central, que constitui o governo federal, e outra descentralizada, que constitui os governos-membro, sendo que ambas têm poderes únicos e concorrentes para governar sobre o mesmo território e as mesmas pessoas (SOARES, 1998, p.3).

O Brasil se reivindica desde a Constituição de 1891 enquanto uma República Federativa. É verdade que o federalismo brasileiro buscou inspiração na experiência americana para formatar as suas instituições, mas as diferenças devem ser prontamente anotadas. As características desiguais do desenvolvimento das diversas regiões são uma marca constitutiva do federalismo brasileiro, o qual não convive com características de plurinacionalidades ou distinções religiosas que justificassem o modelo. Em verdade, o estado brasileiro nunca reconheceu e/ou utilizou como pré-requisito para sua organização institucional a existência de nacionalidades originárias, ou seja, as várias etnias indígenas nunca foram levadas em consideração na formatação dos desenhos institucionais (SOUZA, 2005).

O modelo de federalismo brasileiro reconheceu autonomia para três entes federados: a União, os Estados e os Munícipios, e inscreveu no texto constitucional as responsabilidades de cada um destes entes federados. Em termos teóricos, a federação advém de um pacto que implica a igualdade de autonomia de seus membros e a mesma possibilidade de participação para a construção da vontade política do estado federal. Assim, o equilíbrio federativo "depende da dosagem das competências e da garantia de fontes de recursos suficientes para que cada ente possa preservar sua autonomia financeira e assim sustentar os encargos decorrentes da prestação de serviços de sua competência" (Martins, 2011, p. 29).

Porém, o modelo de federalismo brasileiro está inserido nas denominadas "soluções de compromisso", tão características das formulações que emergem do processo constituinte de 1988, e é uma combinação entre o desejo de descentralização de poder e a histórica primazia do papel regulador e indutor do poder central em nosso país.

O processo de globalização econômica que se aprofundou no mundo na década seguinte à promulgação do texto constitucional provocou desequilíbrios na fórmula federativa brasileira. Este processo é caracterizado 
pelo despojamento, de uma forma cada vez mais acentuada, dos governos nacionais diante das suas clássicas atribuições, e no interior de cada país o mesmo processo se reproduz através de um "efeito cascata", sendo que o governo central saqueia e viola municípios e estados. Estes, por sua vez, também aplicam essa receita aos municípios. Enfim, o arranjo federativo constitucionalmente pactuado é tornado letra morta (RODRIGUES, 2012).

Neste contexto de reforma do estado, "a descentralização passou a ser encarada como um fator capaz de gerar eficiência no sistema de oferta de políticas públicas. Tal descentralização veio acompanhada da centralização no processo de definição de políticas" (CRUZ, 2012, p.71). De forma contraditória, enquanto a Carta permitiu a alocação de mais recursos para unidades subnacionais, diminuindo receitas do poder central, ao mesmo tempo foram criados sistemas de controle em um movimento re-centralizador, cujo exemplo mais paradigmático foi a aprovação, na década seguinte, da Lei de Responsabilidade Fiscal. Além disso, presenciouse um movimento de recomposição da base tributária nas mãos da União por meio de criação de contribuições sociais, as quais fugiram da necessidade de repartição com unidades subnacionais e a redefinição de alíquotas.

Quase três décadas de vigência do modelo federativo promulgado em 1988 não foram suficientes para que as regras de repartição de recursos e responsabilidades fossem devidamente regulamentadas. O parágrafo único do seu artigo 23 continua sem o devido detalhamento e o esperado regime de colaboração entre os entes federados é ainda impreciso e desequilibrado.

Esta situação fica evidente ao analisarmos a distribuição dos recursos destinados à educação pública por entes federados. O último dado disponível (2012) demonstra que a União contribui com 18,2\% dos recursos aplicados, participação bastante desproporcional ao seu potencial arrecadatório. Essa fraca participação, que não sofreu variações na última década (em 2000 a União participou com 17,9\%), sobrecarrega os demais entes federados na prestação dos serviços educacionais e reforça os traços desiguais na oferta educacional, ou dizendo de outra forma, favorece a existência de diferentes padrões de qualidade.

\section{O debate sobre regime de colaboração no PNE}

O artigo 211 da Constituição Federal, reconhecendo a complexidade do modelo desconcentrado de prestação de serviço educacional instituído pelos artigos precedentes afirma que "a União, os Estados e os Municípios organizarão em regime de colaboração seus sistemas de ensino". Tal afirmação é oriunda do caráter concorrencial da matéria educacional, pois é afeita a todos os entes. Porém, "se temos uma educação nacional, não temos um sistema nacional de educação. Nacional é a educação, não o sistema" (CURY, 2007, p. 124).

A falta de regulamentação de um regime de colaboração na área educacional torna a tarefa de formulação e posterior implementação de um Plano Nacional de Educação ainda mais complexa. Independente desta lacuna, articular metas e estratégias a serem cumpridas durante dez anos por 5570 municípios, 26 estados, um Distrito Federal e a União, por si só envolve muitas variáveis e enormes dificuldades operacionais, exigindo um nível de trabalho conjunto inexistente em nosso país.

O termo "regime de colaboração" aparece 21 vezes no texto da Lei n 13.005 de 25 de junho de 2014. Porém, é forçoso registrar que após vinte e seis anos de vigência da Constituição Federal e de sua previsão de materialização de um regime de colaboração, uma parte das citações ainda ficaram no terreno das boas intenções.

Os avanços mais relevantes na busca de criar um regime de colaboração estão inscritos no artigo $7^{\circ}$ da referida norma e em alguns dos seus parágrafos. No caput do artigo é repetida a necessidade de atuação conjunta dos entes federados, visando o alcance das metas e estratégias do plano, mas no parágrafo $5^{\circ}$ temos a obrigação de constituir uma "instância permanente de negociação e cooperação entre a União, os Estados, o Distrito Federal e os Municípios". E no parágrafo $6^{\circ}$ é dito que "o fortalecimento do regime de colaboração entre os Estados e respectivos Municípios incluirá a instituição de instâncias permanentes de negociação, cooperação e pactuação em cada Estado". 
A falta de regulamentação do regime de colaboração gerou dois fenômenos nocivos ao equilíbrio federativo e à garantia do direito à educação. De um lado, houve clara sobrecarga de alguns entes federados, especialmente os municípios, que assumiram mais responsabilidades do que previsto na Constituição (a oferta do ensino fundamental é exemplar) e tais atribuições não foram acompanhadas de alocação de recursos proporcionais. De outro lado, houve concorrência entre estados e municípios e uma relação de subordinação da esfera municipal, fruto do padrão de relacionamento político existente em muitas unidades da federação.

A tradição patrimonialista ganha farto espaço de teimosa persistência, regulando-se caso a caso, na forma de convênios pontuais e temporários, decretos ocasionais e, até mesmo, acordos informais entre "autoridades educacionais". É evidente que, num quadro destes, os princípios proclamados pela Constituição ficam sumariamente relativizados ao sabor do entendimento político dos governos de turno em cada unidade federada (ABICALIL, 2002, p. 256).

As redações dos dois parágrafos, caso se concretizem, colaboram para diminuir o cenário descrito por Carlos Abicalil há doze anos e que permanece bastante representativo das relações entre os entes federados em nosso país.

Além disso, o exemplo de funcionamento da área da saúde, onde existem instâncias de negociação entre os entes (trilateriais e bilaterais) poderá servir de parâmetro para a construção de uma nova experiência na área educacional. A diferença, que é muito relevante, é que a saúde optou por um Sistema Único já durante o processo constituinte e a educação manteve um formato desconcentrado de funcionamento e só recentemente a discussão sobre um Sistema Nacional de Educação voltou a ganhar força. Aliás, o novo Plano Nacional de Educação, no seu artigo 13, estabelece um prazo para que esta lacuna seja superada.

Art. 13. 0 poder público deverá instituir, em lei específica, contados 2 (dois) anos da publicação desta Lei, o Sistema Nacional de Educação, responsável pela articulação entre os sistemas de ensino, em regime de colaboração, para efetivação das diretrizes, metas e estratégias do Plano Nacional de Educação.

Em diversas estratégias do PNE a questão do regime de colaboração se apresenta. No geral, mesmo que exista previsão constitucional clara de a qual ente federado cabe a responsabilidade pelo provimento educacional de dada etapa ou modalidade, a capacidade do ente em cumprir a meta ou estratégia estabelecida no plano é insuficiente para que a mesma se concretize. Assim, cabe ajuda dos demais entes federados.

Na Meta 01, que trata da expansão das matrículas de educação infantil, o regime de colaboração aparece em três estratégias. Ele se faz necessário para garantir as "metas de expansão das respectivas redes públicas de educação infantil segundo padrão nacional de qualidade, considerando as peculiaridades locais" (Estratégia 1.1). Para que seja feito o levantamento da demanda de creche para a população de até 3 (três) anos também a lei reconhece a necessidade de apoio dos demais entes aos municípios (Estratégia 1.3). E, na estratégia mais concreta, a manutenção e ampliação de "programa nacional de construção e reestruturação de escolas, bem como de aquisição de equipamentos, visando à expansão e à melhoria da rede física de escolas públicas de educação infantil”, deverá também contar com apoio, neste caso, mesmo que não de maneira explícita, a Estratégia 1.5 se refere a aporte federal já existente e que necessita de ampliação.

Um dos desafios do novo Plano Nacional de Educação é ampliar o número de escolas com tempo integral na educação básica. A Meta 06 estabelece dez anos para o Brasil ter tempo integral em 50\% (cinquenta por cento) das escolas públicas, de forma a atender, pelo menos, 25\% (vinte e cinco por cento) dos(as) alunos(as) da educação básica. Para isso será fundamental um "programa de construção de escolas com padrão arquitetônico e de mobiliário adequado para atendimento em tempo integral", o qual precisará ser feito em regime de colaboração, conforme Estratégia 6.2. Da mesma forma, a Estratégia 6.3 preconiza colaboração para que se constitua um "programa nacional de ampliação e reestruturação das escolas públicas", pois o desafio é garantir que as atuais escolas tenham quadras poliesportivas, laboratórios, inclusive de informática, espaços para atividades culturais, bibliotecas, auditórios, cozinhas, refeitórios, banheiros e outros equipamentos.

A Meta 7 se propõe a fomentar a qualidade da educação básica em todas as etapas e modalidades e na sua Estratégia 7.19 o novo PNE quer "institucionalizar e manter, em regime de colaboração, programa nacional 
de reestruturação e aquisição de equipamentos para escolas públicas, visando à equalização regional das oportunidades educacionais". Não se pode pretender alcançar indicadores de qualidade sem que as oportunidades educacionais sejam equalizadas, posto que a oferta escolar pública é muito desigual entre as regiões e entre os municípios. Por isso, também na Estratégia 7.21 é colocada a necessidade dos entes federados colaborarem para a construção de "parâmetros mínimos de qualidade dos serviços da educação básica".

Seguindo o mesmo caminho aparecem quatro citações nas Metas 9 e 10, que tratam da educação de jovens e adultos, e que também reclamam por uma atuação colaborativa entre os entes federados.

Se a quase totalidade das metas do Plano precisam de algum nível de colaboração entre os entes, certamente a Meta 15 é representativa desta necessidade. Para garantir uma política nacional de formação dos profissionais da educação, ou seja, para que se desenvolvam esforços formativos para mais de dois milhões de trabalhadores da área educacional é necessário engajamento das instituições do ensino superior (as públicas majoritariamente federais, mas também estaduais) e alocação de recursos que permita a estes trabalhadores se ausentar do local de trabalho para estudar, exigindo enorme esforço financeiro de estados e municípios. Aqui também se fez presente a reivindicação de um regime de colaboração, inclusive para que seja implantada no prazo de um ano, uma política de formação para os não-docentes (Estratégia 15.11).

Da mesma forma, o esforço para elevar o nível de professores com pós-graduação lecionando na educação básica exigirá trabalho conjunto dos entes federados. Pelo menos esta é a assertiva presente na Estratégia 16.1. E, ainda se tratando de docentes, na Estratégia 18.5 é estabelecido que se realize "anualmente, a partir do segundo ano de vigência deste PNE, por iniciativa do Ministério da Educação, em regime de colaboração, o censo dos(as) profissionais da educação básica de outros segmentos que não os do magistério".

Por fim, para completar esta compilação da presença do termo "regime de colaboração" no texto do novo Plano Nacional de Educação, cabe citar a Estratégia 20.9.

20.9) regulamentar o parágrafo único do art. 23 e 0 art. 211 da Constituição Federal, no prazo de 2 (dois) anos, por lei complementar, de forma a estabelecer as normas de cooperação entre a União, os Estados, o Distrito Federal e os Municípios, em matéria educacional, e a articulação do sistema nacional de educação em regime de colaboração, com equilíbrio na repartição das responsabilidades e dos recursos e efetivo cumprimento das funções redistributiva e supletiva da União no combate às desigualdades educacionais regionais, com especial atenção às regiões Norte e Nordeste.

Apesar de redundante, a Estratégia transcrita acima reforça a necessidade de se regulamentar o dispositivo constitucional no que diz respeito à educação. E, passados tantos anos, a lei estabelece novo prazo, no caso dois anos, para que a lacuna seja preenchida por uma Lei Complementar. A referida norma deve seguir, dentre outras preocupações, o equilíbrio na repartição das reponsabilidades e tratar da efetivação do cumprimento das funções redistributivas que cabem à União.

Certamente a efetivação de ações redistributivas por parte da União passam pela equalização das oportunidades educacionais e este tema está profundamente associado à criação de um padrão mínimo de qualidade. A Constituição de 1988, ao instituir a educação como um direito social (caput do Artigo $6^{\circ}$ ), expresso como direito de todos e dever do Estado (Artigo 205), não partiu de uma situação de inexistência de oferta educacional. Pelo contrário, os avanços ali registrados são fruto da consolidação de um sistema educacional descentralizado e com padrões de oferta muito diferenciados.

Diante de um quadro em que a oferta educacional não estava garantida para todos e, ao mesmo tempo, havia forte questionamento social acerca da qualidade dos serviços prestados (neste momento muito subordinado à não garantia de permanência dos estudantes que conseguiam ingressar nas escolas), a Constituição consignou como um dos princípios que deveriam reger o ensino a "garantia de padrão de qualidade" (Artigo 206, VII).

Foi justamente a busca por concretizar este princípio constitucional que se transformou em um dos debates mais polêmicos durante a tramitação do novo Plano Nacional de Educação. O estabelecimento de um padrão mínimo de qualidade foi materializado no indicador desenvolvido pela Campanha Nacional pelo Direito à 
Educação² e sistematizado por Carreira e Pinto (2007) denominado de Custo Aluno-Qualidade. A polêmica se deu principalmente sobre o papel que deveria caber à União após o estabelecimento do referido padrão, ou seja, detectando que muitos estados e municípios estariam abaixo do patamar de qualidade determinado pelo referido indicador, qual seria a participação financeira da União para que o Brasil possuísse este novo patamar de oferta educacional.

20.10) caberáà União, na forma da lei, a complementação de recursos financeiros a todos os Estados, ao Distrito Federal e aos Municípios que não conseguirem atingir o valor do CAQi e, posteriormente, do CAQ.

Depois de idas e vindas legislativas, o texto da Estratégia 20.10, transcrito acima, foi aprovado. Seu conteúdo é diretamente vinculado ao regime de colaboração e à discussão da revisão dos papéis dos entes federados no financiamento educacional. A referida estratégia ensejará uma maior participação financeira da União no financiamento da educação básica. Estudos desenvolvidos pela Fineduca³ (2014) e por Araujo (2013) apontam para a necessidade de significativo aporte financeiro para que o Custo Aluno-Qualidade Inicial seja efetivado. E a redação remete para a União a obrigação de suprir a carência de recursos dos entes federados que não alcançarem o patamar estabelecido enquanto padrão mínimo de qualidade.

\section{Os desafios dos próximos anos}

Comungo da apreciação feita por Araújo (2010) sobre o desafio presente na regulamentação do regime de colaboração.

No processo de regulamentação do regime de colaboração, há que se levar em conta um grande desafio para as relações intergovernamentais no Brasil: 0 estabelecimento de uma justa distribuição de poder, autoridade e recursos entre os entes federados, garantindo a independência e interpenetração dos governos nacional e subnacionais sem que haja comprometimento de um projeto de desenvolvimento nacional, no qual um dos elementos é a educação (ARAUJ0, 2010, p. 764).

Com a aprovação de um novo Plano Nacional de Educação, o debate sobre a regulamentação do regime de colaboração passou a estar presente na ordem do dia da pauta educacional. A "justa redistribuição de poder, autoridade e recursos entre os entes federados" é o grande desafio dos próximos anos. Há uma certeza de que as metas e estratégias presentes no PNE somente serão cumpridas se houver esta redistribuição de responsabilidades e recursos.

Dentre as polêmicas embutidas neste desafio está uma contradição muito relevante. De um lado, existe uma demanda reprimida de maior participação dos demais entes federados nas decisões de alocação de recursos e a descentralização destes de forma proporcional às responsabilidades assumidas. De outro, são justamente as políticas reguladas pela instância nacional que mais eficácia têm mostrado no combate à desigualdade entre os estados e municípios (ARRETCHE, 2010; ARAUJO, 2013). Encontrar o equilíbrio é o desafio teórico e prático. Dito de outra forma, combater as desigualdades passa por rever o papel da União no financiamento, mas necessariamente passa pelo desenvolvimento e/ou aprofundamento de políticas redistributivas reguladas pelo governo central, única forma de induzir comportamentos mais equânimes na aplicação dos recursos na área educacional.

A implementação do Custo Aluno-Qualidade Inicial, previsto para dois anos, conforme a Estratégia 20.6 do PNE, colocará a necessidade de definição, ao mesmo tempo, dos parâmetros de qualidade aceitos socialmente e historicamente pelo Brasil, mas também exigirá, em paralelo, acordos entre os entes federados das formas, dos prazos e da participação financeira de cada ente na materialização do referido padrão.

2 A Campanha Nacional pelo Direito à Educação, neste texto também denominada simplesmente como Campanha, é uma rede da sociedade civil que tem por missão atuar pela efetivação e ampliação dos direitos educacionais para que todas as pessoas tenham garantido seu direito a uma educação pública, gratuita e de qualidade no Brasil. Articula mais de $\mathbf{2 0 0}$ grupos e entidades distribuídas por todo o País. Entre outras conquistas, a Campanha liderou a incidência da sociedade civil na elaboração e regulamentação do Fundeb.

3 A Associação Nacional de Pesquisa em Financiamento da Educação, Fineduca, é uma associação civil de direito privado, que esteve presente nos debates legislativos do novo PNE. 
Da mesma forma, a constituição de instâncias negociadoras entre os entes federados trará à tona o debate sobre o Sistema Nacional de Educação, temática mais ampla do que apenas a repartição de responsabilidades e recursos, que ensejará reflexões acerca dos limites da autonomia normativa dos entes, por exemplo. Uma nova norma legal sobre o tema e a reformulação da Lei de Diretrizes e Bases da Educação se tornarão necessidades prementes.

A esperança é que tais reformulações tornem a oferta de educação uma ferramenta mais efetiva no combate às desigualdades, sejam elas sociais, raciais, de gênero ou territoriais.

\section{Referências}

ABICALIL, C. Sistema Nacional de Educação Básica: nós da avaliação? Revista Educ. Soc., Campinas, v. 23, n. 80, setembro/2002, p. 253-274. Disponível em <http://www.cedes.unicamp.br>

ARAUJO, G. Constituição, federação e propostas para o novo Plano Nacional de Educação: análises das propostas de organização da educação brasileira a partir do regime de colaboração. Revista Educ. Soc., Campinas, v. 31, n. 112, p. 749-768, jul.-set. 2010. Disponível em <http://www.cedes.unicamp.br>

ARAUJO, L. Limites e possibilidades da redução das desigualdades territoriais por meio do financiamento da educação básica. 416f. Tese (Doutorado em Educação). Faculdade de Educação, Universidade de São Paulo, 2013.

ARRETCHE, M. Federalismo e igualdade territorial: uma contradição em termos. Revista de Ciências Sociais, Rio de Janeiro, v. 53, n. 3, 2010, p. 587-620.

BRASIL. Constituição Federal. Diário Oficial da República Federativa do Brasil, Brasília, DF, 05 out. 1988. p. 01 (Anexo).

Lei $\mathbf{n}^{\circ} \mathbf{1 3 . 0 0 5}$, de 9 de janeiro de 2001. Aprova o Plano Nacional de Educação e dá outras providencias. Brasília, DF. Disponível em: http://www.planalto.gov.br/CCIVIL 03/ Ato2011-2014/2014/Lei/L13005.htm. Acesso em 10 de julho de 2014.

CARREIRA, D.; PINTO, J. Custo aluno-qualidade inicial: rumo à educação pública de qualidade no Brasil. São Paulo: Global; Campanha Nacional pelo Direito à Educação, 2007.

CRUZ, R. E. Federalismo e Educação: um pacto a se rever. Retratos da Escola, Brasília, v. 6, n. 10, p.65-78, jun. 2012. Semestral.

CURY, C. Sistema Nacional de Educação: desafio para uma educação igualitária e federativa. Revista Educ. Soc., Campinas, vol. 29, n. 105, p. 1187-1209, set./dez. 2008. Disponível em <http://www.cedes.unicamp.br>

FIORI, J. O federalismo diante do desafio da globalização. In: AFFONSO, Rui; SILVA, Pedro. A federação em perspectiva: ensaios selecionados. São Paulo: Fundap, 1995. p. 20-36.

MARTINS, P. Fundeb, federalismo e regime de colaboração. Campinas, SP: Autores Associados, 2011.

RODRIGUES, E. Território e soberania na globalização: Amazônia jardim de águas sedento. Belo Horizonte: Editora Fórum, 2012. 459 p.

SOARES, M. Federação, democracia e instituições políticas. Lua Nova (on line), São Paulo, n. 44, p.137-163, dez. 1998.

SOUZA, C. Federalismo, desenho constitucional e instituições federativas no Brasil pós-1988. Rev. Sociologia e Política. Curitiba, n. 24, jun. 2005. Disponível em http://migre-me/dOJul. Acesso em 05 dezembro de 2010.

Recebido em agosto de 2014 - Aprovado em setembro de 2014 